in a paper referred to above, was soon afterwards rediscovered and elaborated in so far as it applies to the sigmoid flexure and the descending colon by Cavaillor and Chalier. ${ }^{18}$ The principle applies equally to the operation upon the right side. When carried out thoroughly it results in the colon having as great freedom of movement as the small intestine.

The choice between the two methods of anastomosisside-to-side or end-to-end-has exercised the minds of surgeons for some years. There are advantages in both. If the peritoneal investments are complete in both ends to be united, then end-to-end anastomosis seems to me an excellent method. It is, however, far more difficult to do with accuracy, neatness, and precision; if done in a slipshod manner disaster is bound to follow, leakage will occur from the suture line, and a general peritoneal infection or a localised abscess will be the result. If the serous covering is incomplete in one or other segment of the bowel, then I think it more prudent to close the two cutends and to approximate their serous surfaces in a side-to-side anastomosis, which should always be of ample size. Healing in such an attachment occurs readily, and the union is sound and firm within a few hours. It has been supposed, and the supposition receives undoubted support from experimental observation, that an endto-end anastomosis allows a more easy onward progression of the intestinal contents. It may be so, but $I$ have never seen any difficulty arise in my own cases when the anastomosis has been made laterally. And as Dr. W. J. Mayo, whose experience is unrivalled, points out, the side-to-side anastomosis seen a few months after its formation differs from the end-to-end very slightly in appearance; a small elbow alone marks the point at which the junction has been made. ${ }^{19}$

\section{THE KINETIC THEORY OF SHOCK AND ITS PREVENTION THROUGH ANOCI- ASSOCIATION (SHOCKLESS OPERATION).}

BY GEORGE W. CRILE, M.D.

\section{Introduction.}

WHEN a barefoot boy steps on a sharp stone there is an immediate discharge of nervous energy in his effort to escape from the wounding stone. This is not a voluntary act. It is not due to his own personal experience (i.e., his ontogeny), but is due to the experience of his progenitor during the vast periods of time required for the evolution of the species to which he belongs-i.e., his phylogeny. The wounding stone made an impression upon the nerve receptors in the foot similar to the innumerable injuries which gave origin to this nerve mechanism itself during the boy's vast phylogenetic or ancestral experience. The stone supplied the phylogenetic association, and the appropriate discharge of nervous energy automatically followed. If the stone be only lightly applied there is a discharge of nervous energy from the sensation of tickling, but if the sole of the foot is repeatedly bruised or crushed by the stone shock may be produced. The body has had implanted within it other similar mechanisms of ancestral or phylogenetic origin, the purpose of which is the discharge of energy for the good of the individual.

According to my kinetic theory of shock it is one of these mechanisms-the motor mechanism in particular-which, through its phylogenetic association with injury of the individual, is responsible for the discharge of energy represented by shock. According to this theory, the essential lesions of shock are in the brain cells, and are caused by the conversion of potential energy in the brain cells into kinetic energy at the expense of certain chemical compounds stored in the cells.

There is strong evidence that animals capable of being shocked are animals whose self preservation originally depended upon some form of motor activity. 'In man and other animals this motor activity expressed itself in running and fivbting; hence the motor mechanism comprises the muscles and all the organs that contribute to their activity.
Motor activity is exclted by the adequate stimulation of the nerve ceptors, both of the contact ceptors in the skin and in other tissues, and of the distance ceptors or special senses. I assume that stimulation of the distance ceptors (special senses) is as potent as stimulation of the contact ceptors in producing a discharge of energy. I assume, further, that the environment of the past (phylogeny). through the experience of adaptation to environment, predetermines the environmental reactions of the present. In each individual at a given time there is a limited amount of potential energy stored in the brain cells. Motor activity, expressed as action or emotion, following upon each stimulus, whether traumatic or psychic, diminishes by so much the amount of potential energy left in the brain cells. Stimuli of sufficient number or intensity inevitably cause exhaustion or death. If this motor activity, resulting from response to stimuli, takes the form of obvious work performed, such as running, the phenomena expressing the depletion of the vital force are termed physical exhaustion. If the expenditure of vital force is due to traumatic or to psychic stimuli which lead to no obvious work performed, especially if the stimuli are strong and the expenditure of energy is rapidthe condition is designated "shock." Shock may, of course, be produced by physical injury without_anæsthesia. The first question then is :

\section{Does Inhalation Anesthesia Prevent Shock?}

The word anæsthesia - meaning without feeling-describes accurately the effect of inhalation anæsthetics. Although no pain is felt in operations under inhalation anæsthesia, the nerve impulses set up by a surgical operation reach the brain. We know that not every portion of the brain is fully anæsthetised, since surgical anæsthesia does not kill. The question then is, What effect has trauma under surgical anæsthesia upon that portion of the brain that remains awake? If in surgical anæsthesia the traumatic impulses of operation cause an excitation of the wide-awake cells, are the remainder of the cells of the brain, despite anæsthesia, influenced in any way? If influenced, they are at least prevented by anæsthesia from expression through conscious perceptions or muscular action.

We determined whether or not the "anæsthetised" cells are influenced by trauma under inhalation anxsthesia by noting in patients the physiological functions after recovery from anæsthesia and by examining the brain cells of animals which had been subjected to shock-producing trauma. It has long been known that the vaso-motor, the cardiac, and the respiratory centres discharge energy in response to traumatic stimuli applied to various sensitive regions of the body during surgical anæsthesia. Our experiments have shown that if the trauma is sufficient, exhaustion of the entire brain may be observed after the effects of anæsthesia have disappeared; that is to say, despite the complete paralysis of voluntary motion and the loss of consciousness due to inhalation anæsthesia, the traumatic impulses do reach and influence every other portion of the brain. We observed also that in every instance the changes in the brain cells of the cortex and of the cerebellum were more marked than in those of the medulla and the cord. (Fig. 2.)

There is also strong negative evidence that traumatic impulses are not excluded by ether anæsthesia from that part of the brain that is apparently asleep. For if the factor of fear be excluded, and if in addition traumatic impulses are prevented from reaching the brain by blocking the nerve trunks by local anæsthesia, then, despite the intensity or the duration of the trauma, within the zone so blocked no exhaustion follows after the effect of the anæsthetic disappears, and no morphologic changes are noted in the brain cells. Still further negative evidence that inhalation anæsthesia offers to the brain cells little or no protection from trauma is derived from the following experiments. Dogs whose spinal cords have been divided at the level of the first dorsal segment and that have then been kept in good condition for two months show a recovery of the spinal reflexes, such as the scratch reflex. Animals so treated are known as "spinal dogs." Now in a "spinal dog" the abdomen and the hind extremities have no direct nerve connexion with the brain. For four hours at a time we submitted such dogs to a continuous severe trauma of the abdominal viscera and of the hind extremities. There resulted bat slight change in either the circulation or the respiration, and no microscopical alteration of the krain cells 
was noted. (Fig. 3.) Judging from a large number of experiments on normal dogs under ether, such an amount of trauma would have caused, not only a complete physical exhaustion, but also a morphologic alteration of all the brain cells and the physical destruction of many ; indeed, it would quite surely have killed the animal. We must, therefore, conclude that, although ether anæsthesia produces unconsciousness, it is in reality only a veneer, as it vrotects none of the brain cells against exhaustion from the tranma of surgical operations.

The Cause of the Exhaustion of the Brain Cells from Trauma of Various Parts of the Body under Inhalation Anosthesia.

First, Are the brain cell changes due to anæsthetics per se? Numerous experiments on animals to determine the effect of ether anæsthesia per se-that is, ether anæsthesia without trauma-showed neither the characteristic physiologic exhaustion after the anæsthesia had worn off nor characteristic changes in the brain cells. Observation of the behaviour of individuals under deep and under light anæsthesia during physical injury at once gave the cue to the carse of the discharge of energy, the consequent physiologic exhaustion, and the morphologic changes in the brain cells. Under surgical anæsthesia, if rough handling of sensitive tissues is made, there is observed usually a marked increase in the respiratory rate and an alteration in blood pressure. Under light anæsthesia severe manipulation of the peritoneum often causes such vigorous contractions of the abdominal muscles that the operator may be greatly hindered in his work. Muscular response to trauma under inhalation anæsthesia may be only purposeless moving, but if the anæsthesia is sufficiently light and the trauma is sufficiently strong, movements, unmistakably purposive, may be produced. To injury under inhalation anæsthesia every grade of response may be seen, varying from the slightest change in the respiration or change in the blood pressure to a vigorous defensive struggle. As to the purpose of these subconscious movements there can be no doubt-they are efforts to esoape from injury. The respiratory centres and the circulatory centres are doing their part in crying out-in trying to escape. So, too, all the rest of the brain cells are doing their part in crying out, in trying to escape, but because of the anzsthetic paralysis the voluntary muscles cannot express themselves. Were it not for the muscular paralysis the patient's face would without doubt express motor activity as strongly as in the accompanying picture of the athlete (Fig. 4) whose motor mechanism is driven by voluntary impulses only. The motor mechanism of a patient under inhalation anæsthesia may be driven even more powerfully, though in silence, throughout the course of a surgical operation.

The result is the same as it would be if a major surgical operation were to be performed under curare alone. Curare completely paralyses all voluntary muscles, but produces no anæsthesia. It gives, therefore, complete muscular relaxation-a dead paralysis that would satisfy the roughest surgeon. During such an operation there would be absolute stillness, but after the paralysing effect of the curare had worn off and the patient had become again able to express himself what would he say? What would the surgeon think? Yet this is just the punishment the surgeon inflicts daily on the subconscious brain, and this explains why a patient in the flood of health and with composed face may emerge broken and shattered and with the facies of the tortured from a severe, perhaps rough, operation under inhalation anæsthesia.

If the trauma under inhalation anæsthesia be sufficiently strong and if it be repeated with sufficient frequency, the brain cells will finally be deprived of so much of their potential energy that they will become exhausted. The resulting exhaustion is the same as that which follows a strenuous and too prolonged muscular exertion, such, for example, as running a Marathon. (Fig. 4.) Whether the nerve energy of the brain is discharged by injury under anzsthesia, by normal physical exertion, or by emotion, identical morphologic changes are seen in the brain cells. The impairment of function in shock from injury, in exhausEion from overwork, and in exhaustion from pure fear is the same. In each a certain length of time is required to effect recovery, and in each morphologic changes in the brain cells are produced. (Compare Fig. 3 and Fig. 10.)

The next questions are these: Is shock produced with equal facility under ether and under nitrous oxide? and What effect has local anæsthesia?

\section{The Ancesthetic Faotor in Shook.}

Assuming that the morphologic changes in the brain cells are due to the fact that nervous energy is produced by the conversion of certain chemical compounds in the brain cells into simpler compounds, and that this conversion of potential energy into kinetic energy is due to oxidation, then one would expect to find that a given amount of trauma under an anæsthetic like nitrous oxide would produce less change than an equal amount of trauma in an animal under ether; for nitrous oxide, more than ether, owes its anæsthetic property to its interference with the use of oxygen by the brain cells. Testing this point experimentally, we found that under approximately equal trauma the changes in the brain cells were approximately three times as gxeat under ether anæsthesia as under nitrous oxide anæsthesia; that the fall in the blood pressure was on the average two and a half times greater under ether than under nitrous oxide (Fig. 5); and finally, that the condition of the animal was better after trauma under nitrous oxide than after equal trauma under ether. In the course of operations on the human body one observes constantly the same protective effect of nitrous oxide. This, however, is what one should expect if the kinetic theory of shock is true. Then, too, the mere excitation due to the feeling of suffocation while inhaling ether causes a certain amount of exhaustion. On the kinetic theory no shock could be produced by traumatising a territory infiltrated with local anæsthetics-a territory whose nerve connexion with the brain has been broken by nerve blocking, thus reproducing the condition of a "spinal" dog whose cord has been divided in the upper dorsal region. Our experiments showed that neither brain cell changes nor physical exhaustion were produced by any trauma, however severe or prolonged, inflicted upon a "blocked" territory. We concluded, therefore, that the traumatic impulses must reach the brain to cause shock. (See Fig. 3.)

We have not yet shown, however, that the brain cell changes are not due to some secondary factor, such as internal secretions, altered gases in the blood, or other metabolic changes.

\section{Are the Brain Cell Changes due to Internal Secretions or to Altered Gases in the Blood?}

If the kinetic theory of shock be correct, then if the circulation of two dogs be so anastomosed that the blood streams of both animals freely intermingle and if only one animal be traumatised, the functional impairment and the brain cell changes will be limited to the animal receiving the injury; but if shock be due to the production of some noxious secretion, to some poisonous product of metabolism thrown into the blood stream, secondarily affecting the brain, or if shock be due to gaseous changes in the blood caused by trauma, then both dogs should suffer equally.

Our experiments were as follows. The proximal end of one carotid artery of Dog A was anastomosed with the distal end of the corresponding carotid artery of Dog B, and one jugular vein of Dog A was then anastomosed with the corresponding vein of Dog $B$, so that the blood streams of both animals intermingled with entire freedom and in large volume. (Fig. 6.) The dogs were approximately of equal weight and physical condition. For two hours Dog A was traumatised. The animals were killed simultaneously, and their brain cells were studied by parallel technique. The experiment showed brain cell changes-typical shock changes-only in Dog A, the dog whose body had been traumatised, and no brain cell changes in Dog B, whose body had not been traumatised, but through whose brain the blood of the traumatised dog flowed freely during the two hours. This result strongly supports the kinetic theory, and with equal strength opposes any theory which implies that internal secretions, gaseous changes in the blood, or the production of noxious products may secondarily cause brain cell changes. (Fig. 7.)

\section{Does Anamia Alone Cause Brain Cell Changes?}

There remains also the possibility that low blood pressure - anæmia alone-may cause the brain cell changes. We have shown elsewhere the destructive effects of anæmia on the brain cells; that in resuscitation experiments a total anæmia of seven minutes caused fatal brain cell changes and that brain cell changes are also produced by low blood 


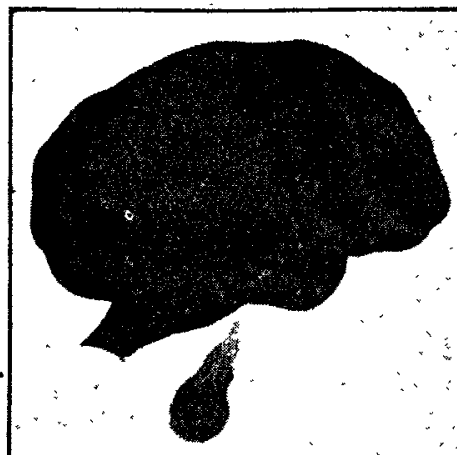

Hyperchromatic.

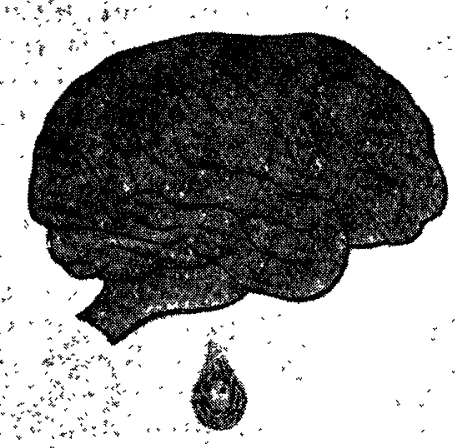

Normal.

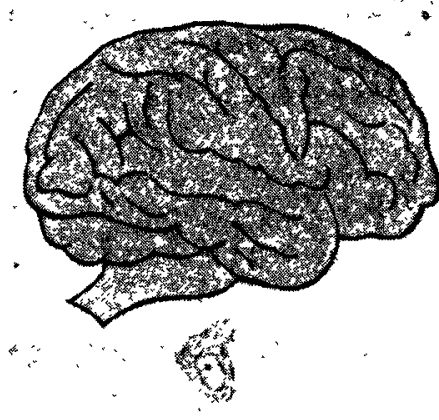

Fatigued.

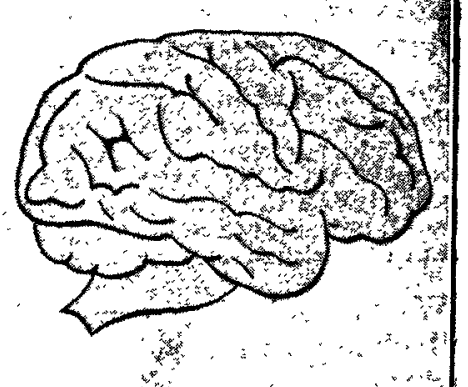

Exhausted.

Fig. 3.-Areas from Cerebellum.

FIG. 2.

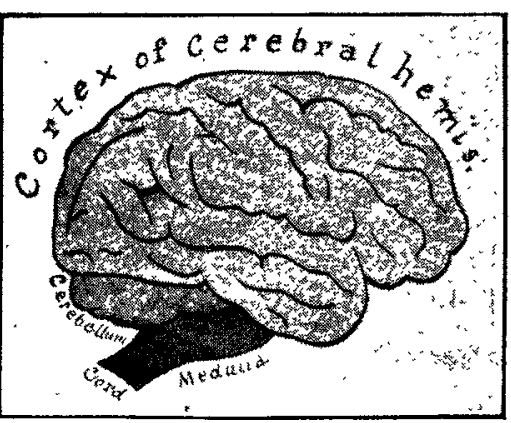

Changes more marked in cortex and cerebellum than in medulla and cord.

FIG. 4.

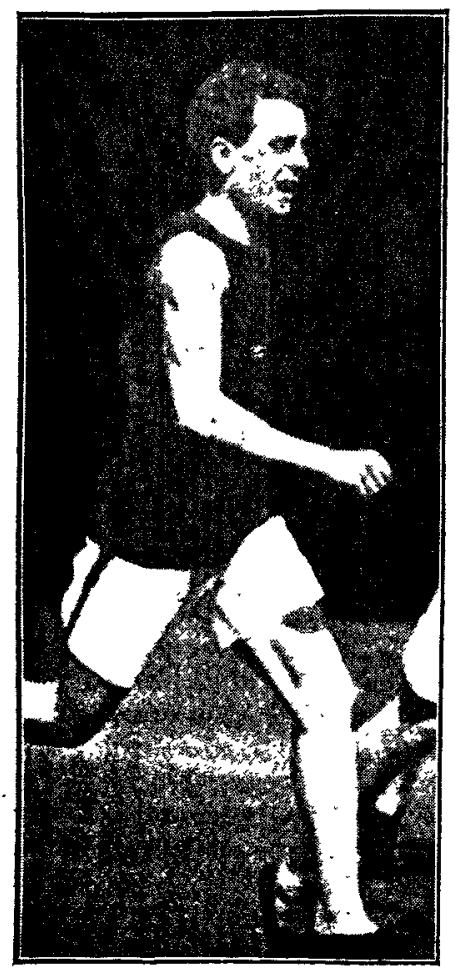

A Marathon runner.
A

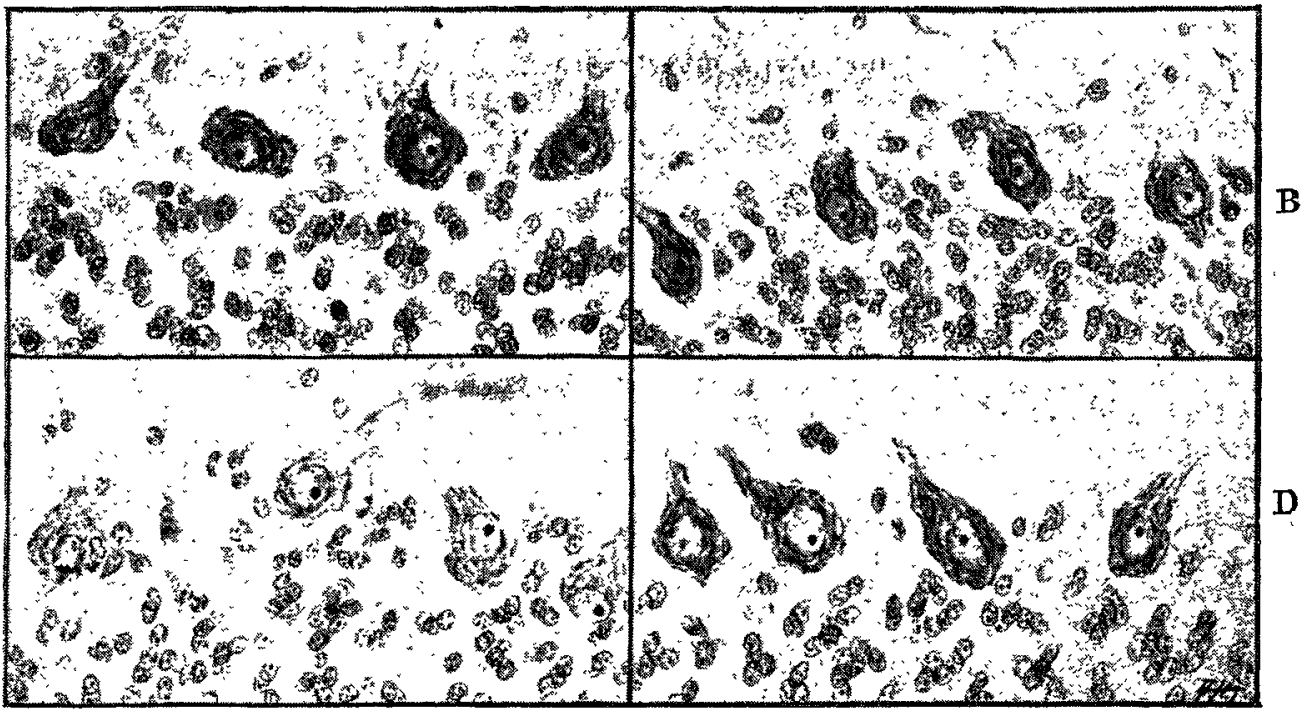

A, Normal dog. B, Shocked "spinal" dog. c, Shocked dog (ether anæsthesia). $\mathrm{D}$, Shocked $\operatorname{dog}\left(\mathrm{N}_{2} \mathrm{O}\right.$ anæsthesia.)

FIG. 5.

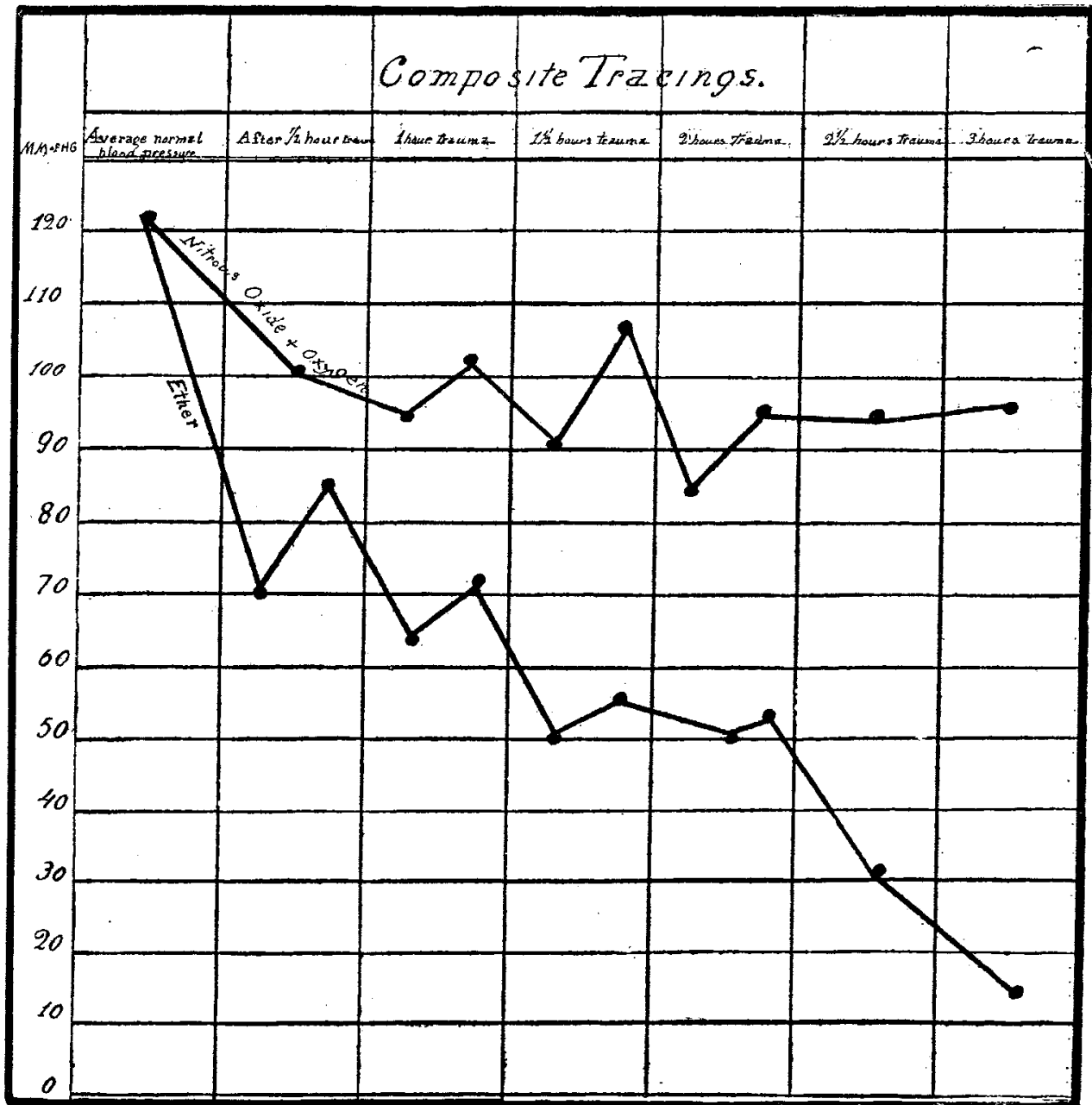


pressure. We had hoped that the brain cell changes in shock were due wholly to low blood pressure, but in our blood transfusion experiments we found that, in addition, there was another definite factor. This was shown by the following experiment.

The blood-vessels of two animals were anastomosed, and as the blood pressure in the traumatised animal began to fall fresh blood was added, so that during the entire séance of shock trauma the blood pressure was maintained at the normal level. Specimens of the brain were removed from the living animal and brain cell changes were demonthan in the animals whose blood pressure was allowed to take its course.

We conclude that anæmia is a factor in producing brain cell changes in shock, yet it certainly is but a secondary factor.

\section{fre Traumata of all Parts of the Body Equally Capable of Producing Shock?}

Innumerable nerve receptors have been implanted in the body for the purpose of effecting adaptation to environment. Some of these receptors, such as those which assist in acquiring food, may be designated beneceptors, while other receptors which have as their function the protection of the body against harmful or nocuous contacts are called nociceptors (Sherrington). As one would expect, therefore, the nociceptors are not distributed throughout the body equally, but are most numerous in those parts which in the course of evolution have been most frequently subjected to injury. So the nociceptors of the skin are most numerous in the hands and the feet, while the back, being less exposed, has fewer mociceptors. Likewise in the interior and more protected parts there are few nociceptors, and there are none in the brain, which has ever been protected by the skull.

If the kinetic theory of shock be correct, then according to the general biologic law of adaptation we should expect that surgical shock could be produced in those parts of the body only in which have been implanted sensitive nerves or nociceptors. On the other hand, since there are few or no nociceptors in those parts of the body which have always been protected against injury and which have not been presented to our enemies and to our rough environment, then, according to this theory, the injury of these parts cannot produce shock. From numerous experiments we find that little or no true surgical shock can be produced by trauma of the deep parts of the back behind the peritoneum ard in the brain.

We therefore took the brain as a representative tissue having no nociceptors or pain nerves, the physical trauma of which could produce an adaptive response, and we put this to a direct experimental test, as follows.

The skull of a dog was cut away under combined local and genera anresthesia. The brain was traumatised with rough gauze and instriments, and was extensively cauterised even to the extent of cradual destruction of one hemisphere.

No noticeable change in the blood pressure was apparent cluring the operation, and no change was observed in the frain cells of the opposite uninjured hemisphere. Our experiment showed, therefore, that the cerebral hemisphere anssess no mechanism for the production of pure surgical shock. Collapse from interference with the medullary centres is, of course, not true surgical shock.

Now, if trauma of sensitive parts of the body produces an adaptive response by the brain cells causing a release of energy, and if this release of energy, when the trauma is sufficiently strong or repeated with sufficient frequency, Beads to functional exhaustion and brain cell changes, then with equal facility exhaustion should be produced by per ceptions through the special senses, such as seeing or hearing danger. Fear and trauma being phylogenetically akin, eithe one alone or associated with the other should cause shock. This point was then studied.

\section{Can Fear Alone Cause Shock.}

This was put to a direct experimental test as follows.

Rabbits were frightened by dogs, but were not injured and were not chased. After various periods of time the animals were killed and their brain cells were compared with the normal.

Widespread changes were seen. The principal clinical ohenomena were rapid heart, accelerated respiration, prostration, tremors, and a rise in temperature. The Jog showed similar phenomena, excepting that instead of muscular relaxation, as in the rabbit, the dog showed aggressive muscular action. Both the dog and the rabbit were exhausted, and although the dog exerted himself actively and the rabbit remained physically passive, the rabbit was much more exhausted. (Fig. 8.)

Observations were made upon the brain of a fox chased for two hours by members of a hunt club and finally overtaken by the hounds and killed. The brain cells of this fox as compared with those of a normal fox showed extensive physical changes in most of the cells. (Fig. 9.) The brains of dogs and woodchucks after fighting showed similar changes. Emotional stimulation alone or combined with physical activity showed the same changes as physical injury. The brains of salmon at the mouth of the Columbia river were compared with the brains of other salmon at the head waters in the spawning season. Like changes were seen. Even the brain cells of electric fish were similarly altered after discharges.

That exhaustion follows fright and terror is attested by every human experience. Fear causes a low threshold, and in that stage the effects of traumatic or psychic stimuli are augmented. A patient going under anæsthesia in fear displays the fear phenomena throughout the operation, and therefore is shocked more readily than if he were without fear.

\section{Insomnia.}

If all the foregoing conditions show brain cell changes characteristic of exhaustion, then keeping animals awake should show the same. The rôle of insomnia in producing exhaustion was put to experimental test as follows: Rabbits were kept awake for 100 hours. They then showed physical exhaustion and the brain coll changes characteristic of fatigue. Sleep restored both the physiologic condition and the physical status of the brain cells. (Fig. 10.)

\section{Influence of other Causes of Vital Depression.}

Again, if the kinetic theory be correct, if an animal has already been subjected to other influences which cause morphologic changes in the brain cells and it be then subjected to trauma, such an animal would be expected to endure less trauma, and survive, than a normal animal. Among the agencies that canse the characteristic changes of fatigue in the morphology of the brain cells are anæmia, infection, toxæmia, physical exercise, old age, starvation, exophthalmic goitre, fear, worry, and physical injury. (These studies will soon be published in detail.) Further observations have shown that just in proportion to the deterioration in the brain cells from any of these factors by so much less can an animal endure injury and survive.

\section{Type of Trauma.}

It may here be added that the intensity of shock depends entirely on the type of trauma to which one is subjected, Tearing, crushing, and bruising cause the greatest shock, while comparatively slight shock would result if the body were cut to pieces with a razor. This observation is so commonplace that its significance is easily lost-namely, that the more nearly the trauma resembles harsh contact with environment and the method of attack of the carnivora, the greater will be the resultant shock.

\section{The Effect of Drugs.}

Such stimulants as strychnine and nicotine in physiologic dosage cause physical exhaustion and brain cell changes. First, there are strong convulsions ; if the dose is repeated the convulsions become milder until the stage of exhaustion is reached. It is as rational to treat the exhaustion of shock with strychnine as to treat the exhaustion of strychnine with trauma. These agencies are synergistic. Alcohol in large doses causes physical exhaustion and brain cell changes. Morphia and scopolamine even in toxic doses cause no apparent changes in the brain cells. The quiet and solace produced by these drugs undoubtedly tend to conserve the output of energy. Morphia and scopolamine in physiologic dosage diminish but do not prevent shock from trauma, but they do prevent psychic shock. Under the influenre of morphia no one is brave, no one is a coward; one is indifferent to danger. This negative state induced by morphia and scopolamine is due to the depression of the asiociational power of the brain--the depression or obliteration of associative memory-and this is an important clinical cue. 
FIG. 6.

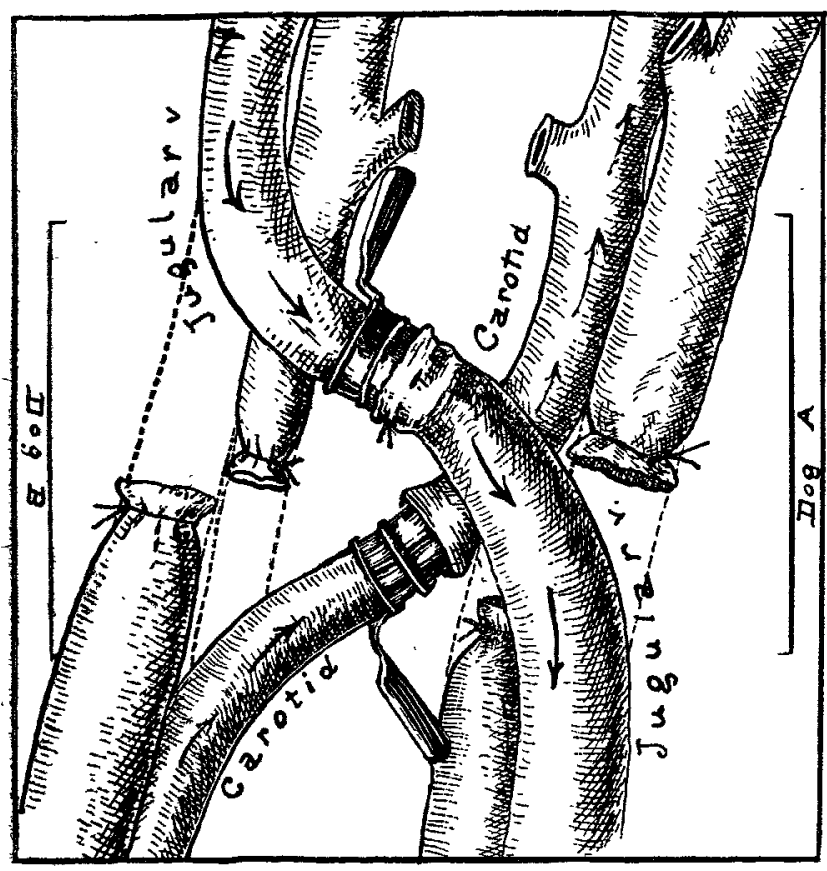

Diagram showing anastomosis of the circulation of Dog A
FIG. 7.

A

Symbiotic shock. Experiment 2 (259A). The cerebellum from the unshocked Dog B (recipient), and from the shocked Dog A (donor).

FIG. 8.

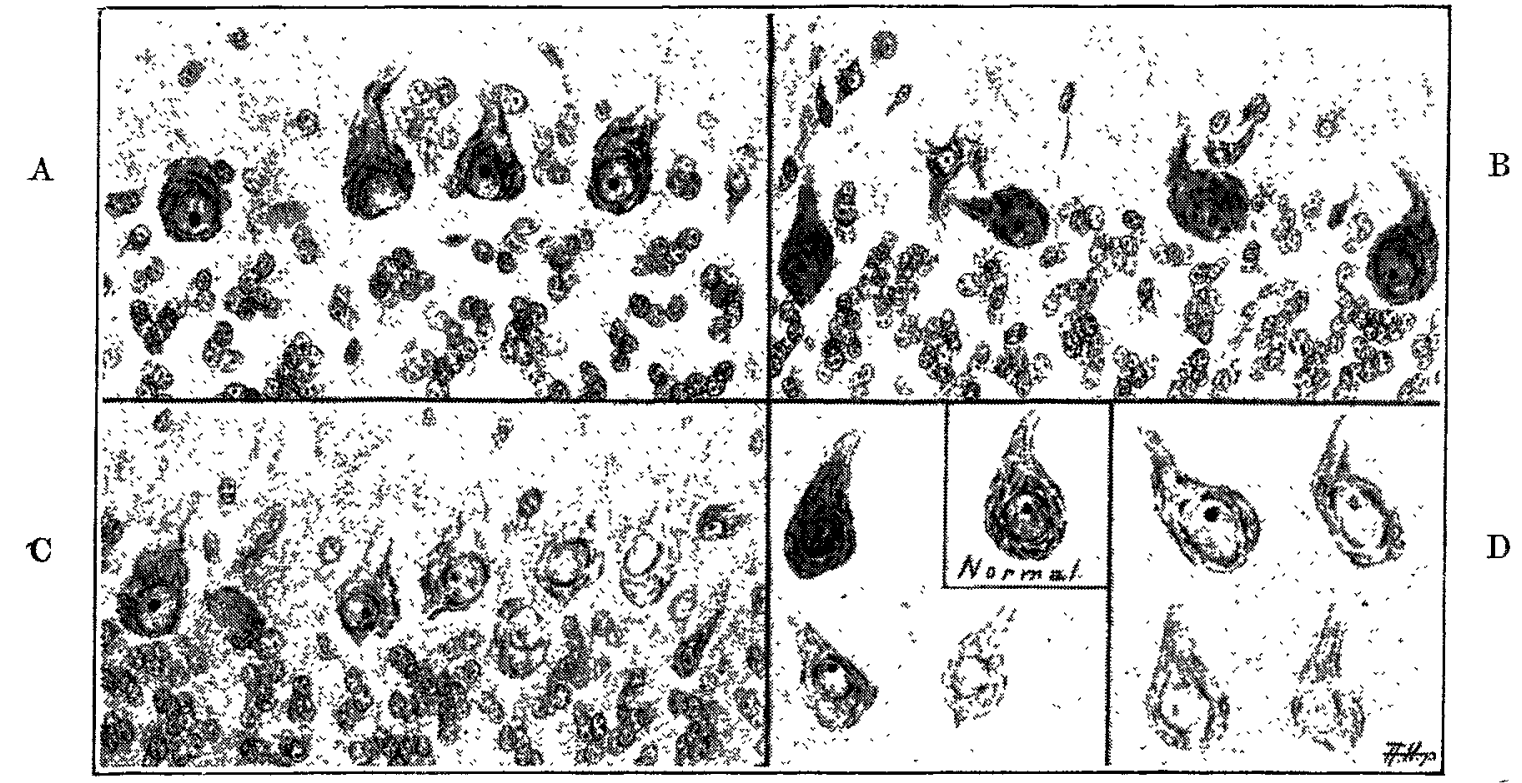

Areas from cerebellum of rabbit. A, Normal rabbit. 'B, Rabbit during fright. c, Six hours after fright. D, Characteristic change in Purkinje cells in fright.

FIG. 9.

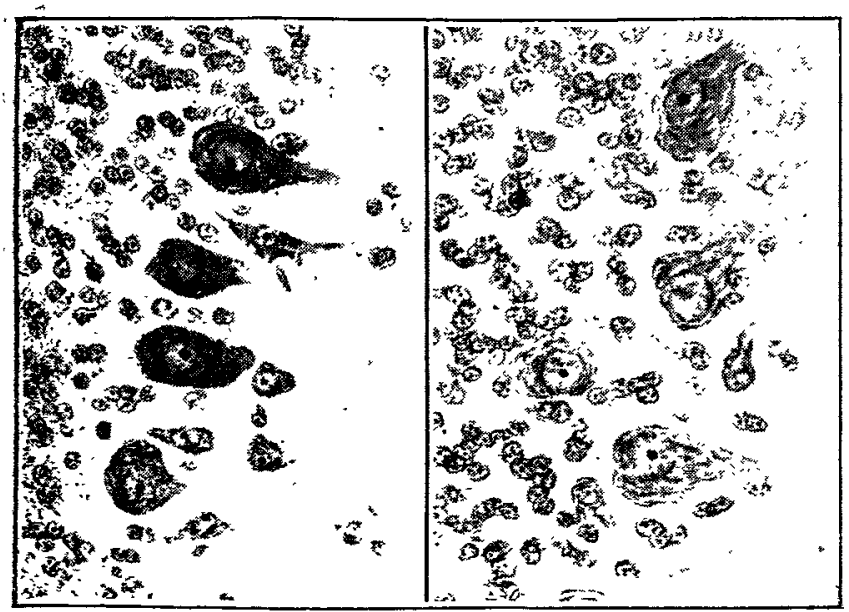

FIG. 10.

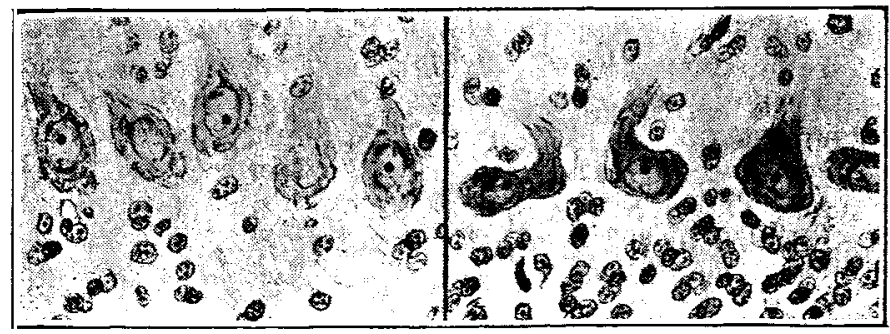

Insomnia. Rahbit awake

Insomnia. Rabbit awake 109 hours. 109 hours ; normal sleep 6 hours. 
The Treatment of Shock.

It is obvious at once not only that stimulants are without value, but that they do harm. Their use is as illogical as is an attempt to ward off bankruptcy by spending more money. Morphia and sedatives generally are valuable as conservators of energy. The one important goal is overcoming the destructive effect of anæmia on the brain. Can this be done by using saline infusions? An extensive research on this point has shown conclusively that the blood cannot be diluted with saline solution, except temporarily. If saline solution is infused continuously into a vein of a normal dog the animal may be killed in from five to eight minutes. What is the cause of death? Is it asphyxia produced by transudation into the lung? No. It is the mechanical fixation of the abdominal and the thoracic respiratory muscles and of the diaphragm through enormous distension of the abdominal viscera. The walls and the lumen of the stomach and intestines are packed with saline; the liver is enormously engorged; the spleen is enlarged; the saline solution runs out through the blood vessel walls just as fast as it enters. Hence in saline solution we have a definitely limited though useful remedy. Posture, bandaging, the pneumatic rubber suit-all are useful, but none is final. The final remedy must be some circulating medium that will remain in the circulation, that will do the work of blood, and that when introduced in large enough quantities will develop a peripheral resistance through stretching the elastic blood vessel. This peripheral resistance based on passive elasticity will then serve as a substitute for the exhausted vasomotor centre. The heart will continue to act so long as the coronary arteries receive a pressure of 40 or more $\mathrm{mm}$. $\mathrm{Hg}$. and as the proper nutriment is given the heart muscle. The only fluid that will answer these purposes is blood-human blood.

Having determined this, I was driven to work out the problem of transfusion of blood, first by experiment in the laboratory, later by practical application in the clinic. This has proven ideal. Almost no case of shock will die of shock alone if given an adequate transfusion of human blood. The transformation is dramatic, especially in shock with hæmorrhage. One hint here in advance of detailed publicationlow blood pressure deteriorates the brain cells, therefore avoid the final collapse by timely transfusion. The transfusion of blood is a specialised technique, the details of which should be mastered in advance of the emergency.

As an interesting sidelight we several years ago found in our investigation that beheaded dogs could be kept "alive" (?) a half day or longer either by slow adrenalin infusion or by over-transfusion of blood, thereby maintaining a normal blood pressure without assistance from the brain.

Having now considered the cause and the treatment of shock as elucidated by our experimental and clinical researches, we will next consider a matter of direct practical importance-viz., the prevention of shock-the shockless operation through anoci-association.

\section{Anoci-association.}

On these foregoing premises the kinetic theory rests. On the kinetic theory a new principle of operative surgery is lounded. This principle can best be expressed by coining a new word-viz., anoci-association. An adequate stimulus with or without inhalation anæsthesia, whether from trauma or from emotion, causes the brain cells to discharge some of their stored energy - that is to say, the sight of the operating room, the spoken word implying danger, the taking of the anæsthetic, the instrumental injury of tissues in the course of the operation, and the traction of the stitches after operation, all are adequate stimuli. Therefore, the stored energy of the brain cells is consumed during surgical operations and during psychic strain. Obviously the only practical method of preventing the consumption of this stored energy of the brain cells is the development of a principle of operative surgery the practice of which will exclude from the brain the stimuli of the special senses and the stimuli of common sensation. This is the principle of anoci-assnciation, meaning the exclusion of all nocuous or harmful associations or stimuli. (Fig. 11.)

The principle of anoci-association may be illustrated by the wrecked Titanic. The story of the stress and the psychic strain of the survivors is known, that of the lost may easily be imagined; the future haunting memory of

this experience by the survivors may be safely predicted. Such is the result of the conventional surgical operation. Now, if a survivor of this ship had been so skilfully anæsthetised on his bed just before the accident that he knew nothing of the impending disaster, and if he then had been gently carried up on deck, lowered into a lifeboat, and taken aboard the rescue ship without being allowed to awaken from his anæsthesia until in bed in a comfortable state-room, - if then he was told that he had been transferred from the sinking ship, but that he was now safe and would soon see his home, this would be anoci-association.

Now is there a single anæsthetic that will exclude all nocuous or harmful physical and psychic stimuli from the brain? By blocking nerve conduction local anæsthetics protect the brain from local operative injury, but they do not protect the brain against destructive psychic strain ; inhalation anæsthetics exclude the psychic stimulation of the brain cells, but do not exclude the operative stimulation;

FIG. 11.

A
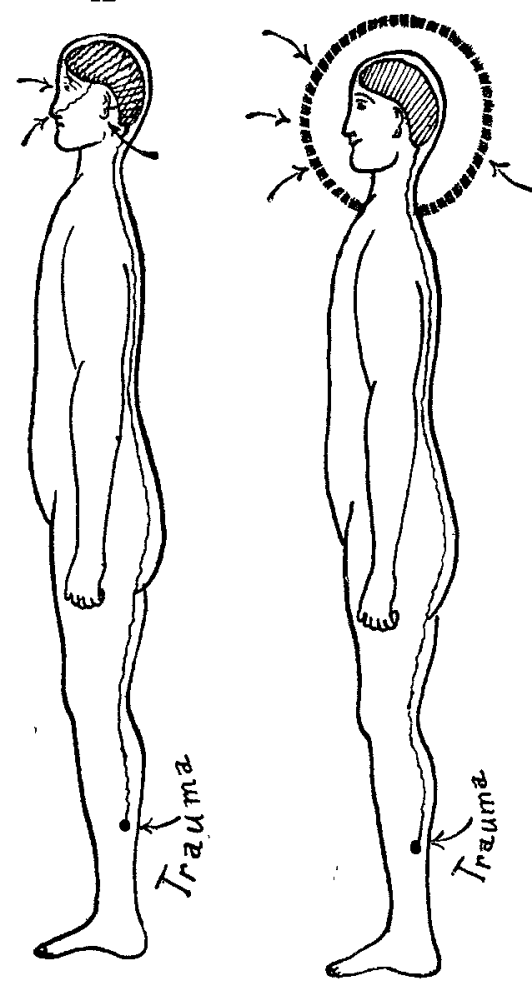

Anoci-association diagram.
C

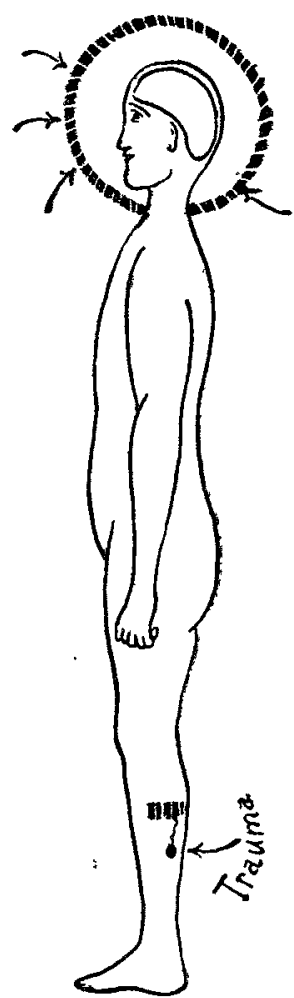

A, Auditory, visual, olfactory, and traumatic noci impulses reaching the brain. $B$, Auditory, visual, and olfactory associations excluded. C, Nerve blocked by cocaine; patient in anoci-association.

and anæsthetics introduced hypodermically, being uncontrollable, are excluded on principle. Each anæsthetic covers a part of the field, but there is no single agent that alone can produce anoci-association, which is the goal of: operative surgery. We therefore do not advocate ether alone, nor chloroform alone, nor nitrous oxide alone; we do not advocate local anæsthesia alone, nor morphine and scopolamine alone, nor spinal anæsthesia alone, but through selection and combination of anæsthetics we aim to attain an anæsthesia that will exclude all stimuli from the brain, and thereby attain anoci-association.

The description of this technique will be limited to abdominal and goitre operations which will serve as illustrations of the principle.

\section{Abdominal Operations.}

1st.-Excluding infancy, old age, and depressed vitality, we first administer, as an average, 1/6th of a grain of morphine and 1/150th of a grain of scopolamine one hour before operation.

2nd.-If local anesthesia alone is employed, novocaine in $1 / 400$ solution is used by progressive local infiltration.

3rd.-If inhalation anæsthesia is employed we administer nitrous 3rd.- If inhalation anæsthesia is employed we
oxide- eitheralone or with ether adder as required. oxide-eitheralone or with ether adder as required.
4 th.-As soon as the patient is unconscious, first the skin and then the subcutaneous tissue is infiltrated with $1 / 400$ novocaine. In order to spread the novocaine immediate local pressure is applied with the hand. Anæsthesia is immediate. Incision through this anæsthetised zone exposes the fascia. The fascia is then novocainised, subjected to presposterior sheath and to the peritoneum. These structures are then 
Fig. 12A.

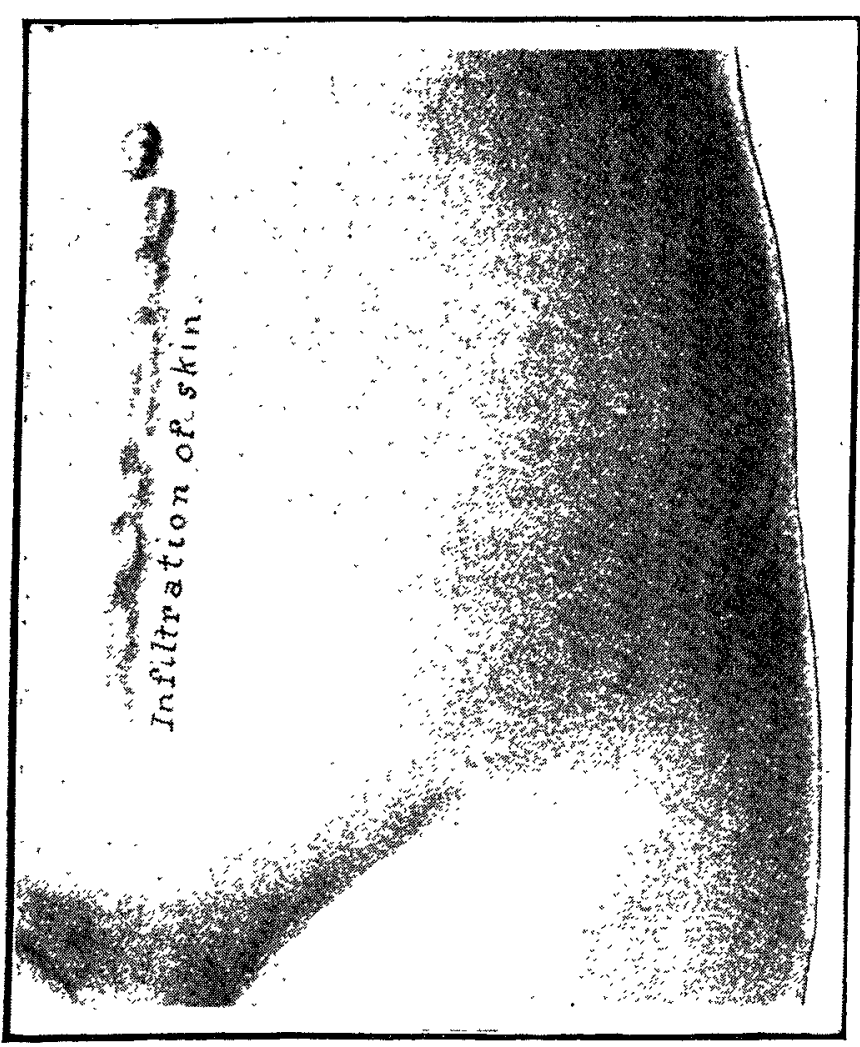

Infiltration of skin and subcutaneous tissue with 1: 400 norocaine.
Fig. 12B.

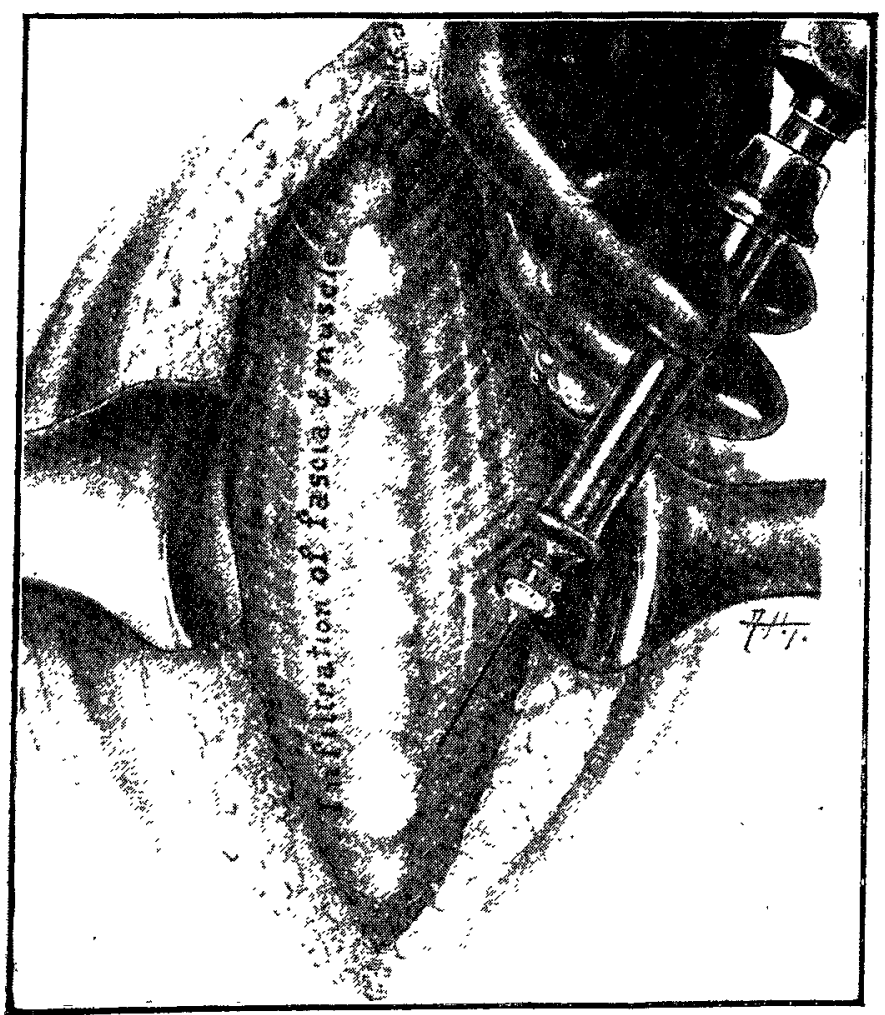

Infiltration of fascia and muscle.

FIG. 12D.

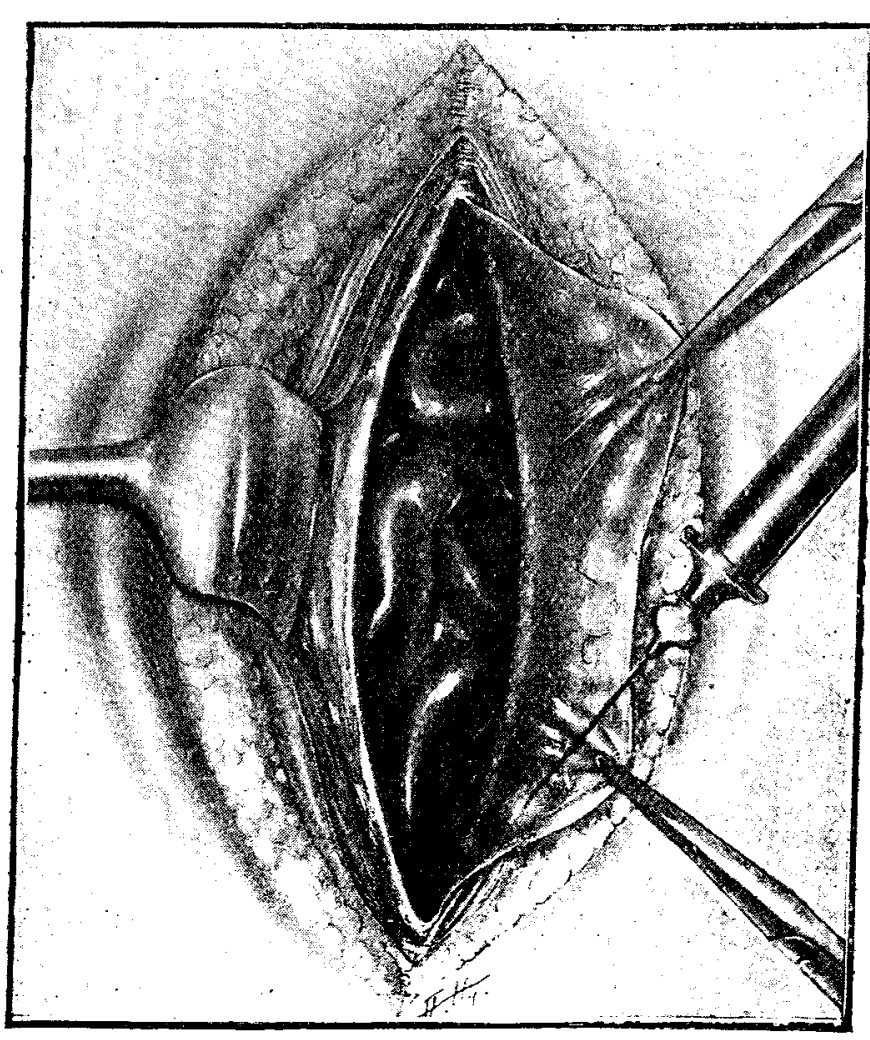

Peritoneum inverted. Infiltration with $\frac{1}{2}$ per cent. of quinine 
infiltrated with novocaine, subjected to pressure, and divided within the blocked zone. If blocking has been complete, then upon opening the abdomen there will be found no increased intra-abdominal pressure, no teniency to expulsion of the intestines, and no muscular rigidity. (Figs. $12 \mathrm{~A}-\mathrm{D}$.

5th. - The peritoneum is next everted and a $\frac{1}{2}$ per cent. solution of quinine and urea hydrochloride is infiltrated about the line of proposed sutures, and as before the parts are then subjected to momentary pressure. This infiltration serves as a block, and as its effects last for several days it should prevent, or at least minimise, the post-operative wound pain and the post-operative gas pains, and by so much minimise post-operative shock. Quinine and urea causes a certain amount of cedema of tissue which lasts for some time after the wound is healed. 6th.-The relaxed abdominal wall will permit exploration of the entire abdominal cavity with ease. If there is no cancer nor acute infection in the field of operation, then the following regions mas be infection in the field of operation, then the following regions may be blocked as completely and in the same manner as the abdominal wallviz., the meso-appendix, the base of the gall-bladder, the uterus, the broad ligaments and the round ligaments, the mesentery, and any portion of the peritoneum. On account of the absence of nociceptors operations on the stomach and intestines made without pulling on tbeir attachment cause no pain, and hence the novocaine infiltration of these viscera is not required. If the brain has received no stimuli during the operation them the closure of the upper abdomen is as easy as the closure of the lower-all is done with the ease of relaxation. What is the result? No matter how extensive the operation, no matter how weak the patient, no matter what part is involved, if anoci technique is perfectly carried out the pulse-rate at the end of the operation is the same as at the beginning. The post-operative rise of temperature, the acceleration of the pulse, the pain, the nausea, and the distension are minimised or wholly prevented. (Fig. 13.)

Fig. 13.

A.

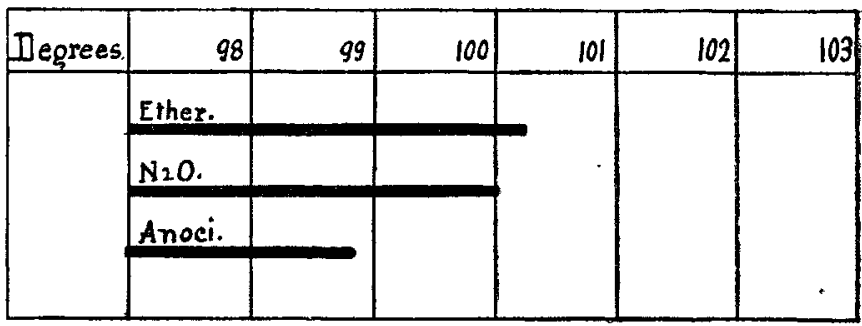

The temperature. Each heavy line represents the average 5 P.M. temperature of 10 patients during the first four days after operation.

B

\begin{tabular}{|l|l|l|l|l|l|l|}
\hline Beats. & 70 & 80 & 90 & 100 & 110 & 120 \\
\hline & Ether. & & & & & \\
\hline & $\mathrm{N}_{2} \mathrm{O}$. & & & & & \\
\hline Anoci. & & & & & \\
\hline
\end{tabular}

The pulse. Each heavy line represents the average 5 P.M. pulse-rate of 10 patients during the first four days after operation.

\section{Graves's Disease.}

I believe everyone will agree that a technique that can carry an advanced exophthalmic goitre case through an operation without increasing the pulse-rate can all the more readily do as much for any other operation. This can be done by the following technique, the operation being either ligation or lobectomy. The patient's consent to an operation is secured before hospital treatment is begun.

Ligation is performed without removing the patient from bed. In performing ligation nitrous oxide and oxygen may or mav not be administered; but the brain is always protected by a complete local blocking with novocaine during operation, and a complete quinine and nrea hydrochloride infiltration at the close of the operation.

nrea hydrochloride infiltration at the close of the operation.
If lobectomy is performed the patient is anæsthetised with nitrous If inbectomy is performed the patient is anæsthetised with nitrous
oxide-oxygen in bed. As fictitious anæsthesia has been given under the oxide-oxJgen in bed. As fictitious anxsthesia has been given under the
guise of treatment for several days previous to the operation, the guise of treatment for several days previous to the operation, the
patient when anzsthetised is free from psychic strain, as he is under

When anæsthetised the patient is taken to the operating-room. The
When the When anæsthetised the patient is taken to the operating-room. The
division of tissue is precered by a blocking so complete that no activating impulse can reach the brain. Before the wound is closed every part of the field is completely blocked by quinine and urea hydrochloride injected with a hypodermic needle. The patient is kept unconscious, under anæsthesia, until he has returned to his room and until his room is restored to its condition when administration of the anæsthetic was begun. Since in the course of the cycle from his room to operation and return hi- brain has received no activating stimuli there can be $n$ change in the pulse. No record of the operation has been written either upon the subconscious brain or the conscious brain.

The benefits do not end, however, with the immediate results. The post-operative hyperthyroidism is prevented or minimised, and the later clinical results are improved to the same extent as are the immediate results.
When a case of Graves's disease which is not under surgical treatment is subjected to a severe psychic shockto a heavy nervous strain or to intense worry-what happens The disease is aggravated for weeks or for months, and not infrequently death results. The evil effects of the stress of facing the operating-room are not only seen immediately, but are perpetuated on the following days and weeks and months by their frequent recall. From this handicap the anoci patient is free, and by so much is the convaleseence speeded on its way.

\section{Comments.}

In carrying out the details of anoci the surgeon must re-educate himself ; his assistants must be especially trained : in short, in the patient's entire cycle of entrance, operation and exit there must be no sharp points of contact, either psychic or physical. Those who have had training in local anæsthesia will find the details easy. This technique will reach its purpose only if rigidly carried out; if carried out perfunctorily as a dull ritual it will fail.

\section{Inhalation Anasthetic.}

The use of nitrous oxide, while not a necessary part, is an important part of the technique of anoci-association. Its greatest value is its protection of the brain cells ; but another advantage is the fact that if the local blocking is faulty or the surgeon needlessly rough, the patient retains still the power of offering a much needed selfprotection. Then, too, ether definitely diminishes the immunity of the patient-nitrous oxide does not.

\section{What Effect has Anoci on the Morbidity and the Mortality?}

The operation morbidity includes the immediate postoperative pain in abdominal operations, gas pains, painful scars, nervousness, reduced efficiency through want of energy, and aseptic wound fever.

Post-operative pain.-Quinine and urea hydrochloride wholly prevents pain if it is injected into the entire wound. But quinine and urea causes some oedema of the wound; hence one should limit the wound infiltration to cases needing it-e.g., exophthalmic goitre cases-bad risks generally.

Post-operative gas pain.-This baffling phenomenon may be largely or wholly prevented by the technique already described-i.e., by the hypodermic infiltration with quinine and urea hydrochloride of a wide margin of tissue, including every part of the divided peritoneum. The stitches must be inserted within the blocked zone. Post-operative gas pain can be explained as a biologic adaptation to overcome infection. In the course of evolution all abdominal penetrations are infected, but the peritoneum is able to overcome most infections if they can be localised. To localise an infection the intestine and the abdominal wall must be kept fixed against each other; that they may do so each must be inhibited ; the intestine must be distended with gas, the abdominal muscle must be rigid. If the intestine be dis tended with gas and fixed then digestion must cease. If digestion be arrested then there is anorexia, or even vomiting to expel food from the stomach. This shows us how post-operative gas pains are due to a biologic adaptation to overcome infection, and explains their resemblance to incipient peritonitis. Nature does not depend upon the surgeon, or perhaps she knows the surgeon too well. The test of this hypothesis is easily made. If the brain through which this adaptive response is made is kept in ignorance of the incision into the peritoneum (a) by progressive novocaine blocking throughout the operation, and $(b)$ by post-operative quinine and urea blocking to break later communication with the brain through stitch tension, then there should be no gas pains. Clinical experience has abundantly confirmed this hypothesis. It must be remembered that if a single nerve filament escapes the block there will be gas pains.

Painful scar.-I postulate that the lesion of a painful scar is in the brain, not in the scar; that it is due to the low threshold produced by injury, and is intimately connected with a fundamental principle of nerve conduction. This fundamental principle relates to the fact that a strong traumatic or psychic stimulus produces some change in the condnctivity along its cerebral arc, the effect of which is that of lowering the threshold of that arc. This might be illustrated by the phenomena following a hold-up at the point of a pistol on a certain street corner. For a long time after such a psychic 
stress any association with that corner would recapitulate the experience. In this manner throughout life various experiences may lower the threshold in innumerable ways. I assume that there is a similar result after a traumatic stimulus. The are receiving the stimulus suffers a lowered threshold, and hence from that time on mere trifles become adequate stimuli. Such a resnlt is seen in the sensitiveness after fraetures and in the painful stumps of crushed limbs.

Now, if an operation is so performed that no strong stimulus reaches the brain either during or after the operation, then the threshold of the cerebral arc from the wound will not be lowered. Since the threshold is not lowered, contact with the scar or any injury to that part will have no more effect than will contact with any other part of the body. In other words, the scar will be no more sensitive than is the skin elsewhere. Hence, we see how painful scar may be prevented by complete anoci. Our clinical data seem to support this hypothesis, although it has not as yet been fully worked out.

Neroousuess. - When in the night one is threatened with an unknown danger the brain threshold is always lowered, apparently as an adaptation to the more swift and accurate detection of the danger. Likewise when one has received a crushing physical injury there is a universal lowering of the threshold. During these states of tenseness minor stimuli have major effects, or, in other words, one is "nervous."

Now, as we have seen, the subconscious brain is tortured directly during unblocked operations under inhalation anæstbesia. The resultant general effect on the brain thresholds is demonstrably the same as if the injury had been inflicted without anæsthesia-i.e., after the ordeal of punishment of the subconscious mind during an operation the patient emerges "nervous," "exhausted "-and since a low threshold is lavish in its waste of nervous energy recuperation is slow. Hence there results a period of postoperative nervousness, of post-operative loss of efficiency. It is obvious-and clinical experience abundantly proves-that the threshold is preserved by complete anoci, hence the anpleasant, damaging post-operative phenomena are avoided.

Lastly, let us consider that curious phenomenon-viz., post-operative aseptic wound fever.

lseptic Wound Ferer in Ordinary Cases and the So-called Post-operatire Hyperthyroidism" in Operations for Exophthalmic Goitre.

Since it is a physical law that any form of force may be converted into heat, and that heat thus produced, if not at once transformed into motion, must increase the temperature of the body affected, we see readily why any stimulus, mechanical or physical, which normally would cause increased motor activity must cause a rise in temperature if complete motor expression is impossible. Anything, therefore, that drives the motor mechanism of the body beyond the point of normal expression will cause fever. Anger, athletic contests, fear, physical injuries, all produce a rapid oxidation of certain body compounds too great for complete translation into motion.

In operations under general anæsthesia only, we expected routinely to see some post-operative rise of temperature as a result of the suppressed power of motor response to the physical and psychical injury; but by the use of anociassociation, both during and after the operation, we discovered a change of post-operative temperature and pulserate. We were therefore forced to the conclusion that, barring infection and the absorption of hæmoglobin, postoperative fever is the result of increased oxidation, this being in turn the result of the psychic and traumatic stimuli of the operation to which natural response has been denied.

These observations lead us to a further knowledge of the phenomena accompanying Graves's disease. This disease is due to a disarrangement of the general motor mechanism whereby the threshold of the brain to both psychical and traumatic stimuli has been lowered in varying degree. The stimulus which in the normal individual would cause no appreciable change in pulse or temperature, will, in a case of Graves's disease, drive the brain and body so fast that greatly increased motor activity and a rise in temperature are caused. Anything, therefore, that raises the threshold of the brain to stimuli must diminish the susceptibility to pulse and temperature changes in the patient suffering from Grares's disease as well as in the normal individual.
This explains why patients under morphia or in a stupor show little change after excitation, and why an operation performed under anoci is followed by diminished or no aseptic fever and in Graves's disease by no so-called " hyperthyroidism."

With these conceptions a surgical operation takes on a new meaning. It becomes a game of biologic chess. The patient never makes the first move, but, through the subconscious brain, counters. The many countermoves of the subconscious brain can be clearly seen and appreciated in changes of the respiration and the pulse, in muscular contractions, in the alteration of muscular tone, in vaso-motor changes, and in pupillary reactions. All of these are responses just as purposeful as the protesting cry or the spoken word of the equally injured but unanæsthetised man. When anoci is carried out perfectly no symbolic protest is made; no change in the threshold is made; no expenditure of nervous energy is made. We must re-educate ourselves so that we can hear the unspoken word; can see the motion in the unmoved muscle. We must practise, not mechanical surgery, but biologic surgery.

We have now stated the kinetic theory of shock and on it have formulated an operative principle (anoci-association), the practice of which enables the surgeon to perform shockless operations. Before stating the clinical results we will discuss more fully certain points and objections to the method.

The first point is the choice of the inhalation anæsthetic and of the anæsthetist. As to the anæsthetic, choice lies between the lipoid solvent anæsthetics, such as ether and chloroform, and nitrous oxide.

Ether anæsthesia has certain advantages. It is relatively safe in inexperienced hands; its bulk is small, it is inexpensive, and requires the simplest apparatus for administration. Against ether stands the malodor; the choking sensation in going under its influence; the drunken nausea sensation when becoming conscious again ; and the fact that the dose required to dissolve the lipoid in the brain suffciently to cause anæsthesia also dissolves the lipoid in the liver, the kidney, the red blood corpuscles, and other important structures. Ether also chemically hinders or prohibits phagocytosis. Hence in addition to anæsthesia this powerful chemical solvent may produce nephritis, pneumonia, anæmia, and many other tissue impairments; besides, in the presence of infection ether arrays itself on the side of infection against the patient. We have already referred to the sense of irritation and suffocation when going under the influence of ether. This is probably the meaning of the "stage of excitement," because the feeling of suffocation is one of the most powerful brain stimulants.

These objections led us to turn to nitrous oxide, an anæsthetic pleasant to take, devoid of baneful after results, and serving as a measurable protection against shock. Against nitrous oxide we found four disadvantages: (1) Its expense; (2) the insufficient muscular relaxation produced ; (3) the difficulty of its administration; and (4) its lack of safety in unskilled hands. If it can be shown that the technical difficulties of nitrous oxide administration can be overcome, that relaxation can be secured and the mortality and the morbidity can be diminished by its use in connexion with local anæsthesia or in certain cases with the addition of ether, then all other questions become ethical issues with the surgeon and the hospital.

If relaxation is incomplete under nitrous oxide alone, then this lack may be met by several minutes of ether administration, or by the addition of a little ether with the nitrous oxide until relaxation is complete.

Let us now turn to the frequently made objection that nitrous oxide in unskilled hands is dangerous. This criticism can be made only by those who wish to advocate filling one of the most critical posts at an operation by untrained hands. This, too, calls for ethical not scientific discussion. The question rather is this, Is nitrous oxide a safe anæsthetic in skilled hands? That question can be answered to this extent: that four skilled anæsthetists have administered nitrous oxide for surgical operations over 18,000 times without an anæsthetic fatality. In unskilled hands I am equally sure nitrous oxide is not safe. The results in untrained hands might be comparable to those of the operation itself if the newest hospital interne were to perform major abdominal and neck operations on his first day of service.

Just as some communities have been terrified by needless 
surgical disasters, just so will some communities be terrified by equally needless anæsthetic deaths from nitrous oxide, probably the safest of all anæsthetics when skilfully given.

The disadvantages of nitrous oxide are almost wholly technical and can be mastered, while the disadvantages of ether are almost wholly chemical, hence not controllable. As already stated, the chemical-hence uncontrollabledisadvantages of ether are : its solvent power over various highly organised fats, such as lecithin in the red blood corpuscles, in the liver cells, kidney cells, and, of course, in the brain cells, and its harmful action in impairing or destroying the immunity of the patient. In close risks with acute infection ether alone may cause death.

The principle of anoci offers a partial solution of this difficulty in the use of ether anæsthesia, which is so satisfactory to the surgeon, so unsatisfactory to the patient. If the field of operation is blocked, then only just enough ether need be given to hold unconsciousness, and so the chemical damage may be reduced quantitatively to the minimum. Far better this combination than nitrous oxide in any but safe hands !

By the introduction of nitrous oxide we have added slightly to the surgical burden. The use of one kind of local anæsthetic for the immediate effect and of another for the later effect in addition to inhalation anæsthesia adds a little more to the burden; the training of the nurses and of the resident staff adds still a little more-in short, the surgical service, and especially the surgeon himself, must undergo a certain amount of re-education, or at least must gain a new viewpoint. Should the burden of the surgeon be thus increased? Here, again, it seems to me the question rather is this: Is it better for the patient? If the morbidity and the mortality are decreased, then this question, too, becomes one of good or bad conduct--of duty. To answer from any other than the patient's viewpoint is the same as if on the morning of a vitally important operation the surgeon were to put to his patient in words the thought that had been in his mind-viz. : "You are about to undergo a dangerous operation. I could lessen the danger by onehalf, and could prevent most of your after-suffering, but because I am too busy a man to bother with the details that would accomplish this, you must take the double chance of suffering and death."

The foregoing is a summary of a large clinical experience and more than 1200 experiments on animals, most of the data of which have been published in detail in five monographs. It is hoped that more monographs of data will be published during this year. We have shown that shock may be produced by physical trauma with or without inhalation anæsthesia; that those parts of the body having the greatest number of nociceptors and which defend the most important regions by muscular action are the most shock-producing on receiving trauma. In the distribution of the defending nociceptors we have a brief epitome of our phylogenetic struggle for existence. We have shown that nitrous oxide anæsthesia as compared to ether anæsthesia is a protective agent against shock-protective through its interference with the use of oxygen by the brain cells-on the same principle as the action of a chemical fireextinguisher. We have shown that the physical exhaustion and the brain cell changes are due to an adaptive response of the brain to the injury-a silent motionless effort to escape from the physical injury of the operation; that if the field of operation is blocked with local anæsthesia, or if the nerve connexion between the brain and the injury is blocked, physical injury can cause no shock. We have shown that the motor mechanism may be powerfully driven by psychic stimuli-perhaps as powerfully as by traumatic and physical exhaustion-and that corresponding brain cell changes are produced. We have seen that if both the traumatic and the psychic stimuli are excluded shock cannot be produced. We have offered evidence that these physical changes in the brain cells are not produced by alteration in the gases in the blood or by metabolic processes from the shock-producing psychic or traumatic stimuli. We have shown that the brain cell changes are not due to anæmia from lowered blood pressure alone. Hence we are forced to conclude that shock is an exhaustion phenomenon due to the driving of the motor mechanism by adequate stimuli, and that it is expressed by physical exhaustion and brain cell changes.
Clinical Results.

We have now presented the theory of shock and a technique by which it may be prevented; but no theory is worth more than its yield in practice, and the only test of laboratory findings is the crucible of the clinic.

The clinical results here reported have been confirmed by the personal experience of Bloodgood, Cabot, and a number of other American surgeons. The accompanying charts show the results of a critical study of the clinical data of parallel series of operations performed at the Lakeside Hospital-the last group of operations under ether alone, under nitrous oxide alone, and under anoci. Were it possible to express the subjective sensations of the patient the contrast would certainly be even more striking. There is no longer need of a post-operative recovery room. The work of the nurse is greatly minimised, and the clinical aspect both in and out of the operating room is altered. My associate, Dr. W. E. Lower, and I during the past year performed 729 abdominal sections of every grade with a mortality-rate of $1 \cdot 7$ per cent. ; and in the Lakeside Hospital Service, where all kinds of acute emergencies are met, and where most of my own private work is done, there were performed by my associates and myself in the past year operations on 2672 patients with a mortality-rate of 1.9 per cent. - a result never before approached in the Lakeside Hospital. In the last 1000

FIG 14.

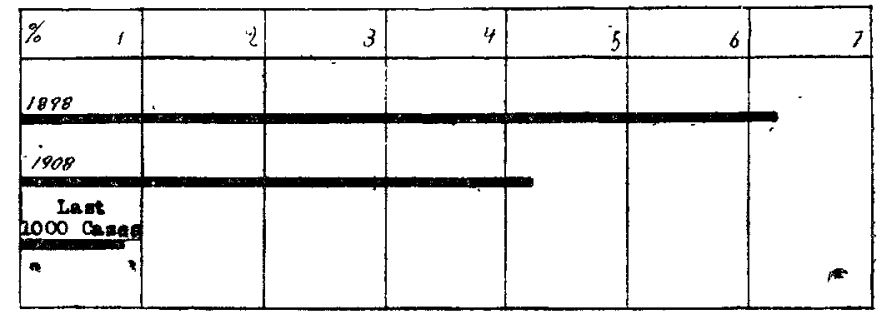

Mortality-rate per 1000 of operative cases, from Lakeside Hospital.

operations performed by Dr. Lower and myself-these operations including every risk of a general surgical practice the mortality-rate has been 0.8 per cent. (Fig. 14.)

Cleveland, Ohio, U.S.A.

The First Inter-Colonial (West Indies) TUBERCULOSIS CONFERENCE.-This conference was held in the Legislative Council Chamber, Port of Spain, from March 25th to 31st, under the patronage of His Excellency Sir George Le Hunte, G.C.M.G. Delegates were present representing Great Britain, the Department of Agriculture, British Guiana, Antigua, Porto Rico, Surinam, Martinique, Barbados, Jamaica, the Municipality of Kingston, Jamaica, Colombia, Venezuela, Grenada, Bermuda, and Trinidad. The President was the Hon. H. L. Clare, SurgeonGeneral for Trinidad. A series of resolutions were passed by the conference referring to the alarming prevalence of tuberculosis in the West Indies, and urging as administrative measures notification, housing reform, and the establishment of tuberculosis dispensaries and other measures for the detection, prevention, and treatment of the disease; the establishment of antituberculosis associations throughout the archipelago; the stamping out of bovine tuberculosis ; the introduction of teaching on hygiene and sanitation in all schools; and the general adoption of efficient registration of births, deaths, and marriages as an aid in controlling tuberculosis. Several interesting papers were read, notably one by Dr. Eliseo Font y Guillot, of Porto Rico, who showed a record of good work in that island by an energetic antituberculosis association, with statutory control of the disease and ample sanatorium provision. An interesting paper was read by Dr. Angus Macdonald, medical officer of health of Kingston, Jamaica, in which he concluded that while in the tropics some things were against them in regard to tuberculosis many were in their favour, and that tuberculosis should not exist in the tropics. The principal adverse feature was unsatisfactory home conditions, crowding, and lack of ventilation at night. Other papers were read by Dr. Hatton, of Grenada; Dr. Dnke, of Antigua ; Dr. Hutson, of Barbados ; Dr. Tucker, of Bermuda; Dr. Ross, of Jamaica; Dr. Noc, of Martinique; Mr. Saunders, veterinary delegate of the Department of Agriculture ; Dr. Godfrey and Miss Hohenkirk, of British Guiana; Dr. Hovenkampf, of Surinam; and Dr. Masson. of Trinidad. 